OPEN ACCESS

Edited by:

Mamdouh El Haj Assad,

University of Sharjah, United Arab

Emirates

Reviewed by:

Willy Villasmil,

Lucerne University of Applied

Sciences and Arts, Switzerland

Muhammad Ahmad Jamil,

Northumbria University,

United Kingdom

*Correspondence: Mohamed Salem salemm@usm.my

Specialty section: This article was submitted to Process and Energy Systems Engineering,

a section of the journal

Frontiers in Energy Research

Received: 21 July 2021 Accepted: 02 September 2021 Published: 07 October 2021

Citation: Alhuyi Nazari M, Salem M, Mahariq I, Younes K and Maqableh BB (2021) Utilization of Data-Driven Methods in

Solar Desalination Systems: A

Comprehensive Review.

Front. Energy Res. 9:742615. doi: 10.3389/fenrg.2021.742615

\section{Utilization of Data-Driven Methods in Solar Desalination Systems: A Comprehensive Review}

\author{
Mohammad Alhuyi Nazari ${ }^{1}$, Mohamed Salem ${ }^{2 \star}$, Ibrahim Mahariq ${ }^{3}$, Khaled Younes ${ }^{3}$ and \\ Bashar B. Maqableh ${ }^{4}$
}

${ }^{1}$ Faculty of New Sciences and Technologies, University of Tehran, Tehran, Iran, ${ }^{2}$ School of Electrical and Electronic Engineering, Universiti Sains Malaysia (USM), Nibong Tebal, Malaysia, ${ }^{3}$ College of Engineering and Technology, American University of the Middle East, Egaila, Kuwait, ${ }^{4}$ Engineering and Technology Department, American College of the Middle East, Kuwait City, Kuwait

Renewable energy sources have been used for desalination by employing different technologies and mediums due to the limitations of fossil fuels and the environmental issues related to their consumption. Solar energy is one of the most applicable types of renewable sources for desalination in both direct and indirect ways. The performance of solar desalination is under effects of different factors which makes their performance prediction difficult in some cases. In this regard, data-driven methods such as artificial neural networks (ANNs) would be proper tools for their modeling and output forecasting. In the present article, a comprehensive review is provided on the applications of different data-driven approaches in performance modeling of solar-based desalination units. It can be concluded that by employing these methods with proper inputs and structures, the outputs of the solar desalination units can be reliably and accurately forecasted. In addition, several recommendations are produced for the upcoming work in the relevant areas of the study.

Keywords: solar desalination, artificial neural network, data-driven methods, renewable energies, review

\section{INTRODUCTION}

Fresh water is absolutely essential for human societies since they rely on it for development and survival (Zheng, 2017). Around $71 \%$ of the earth is covered with water; however, about $96.5 \%$ of this water is in the brackish form or saline, which means that it cannot be directly used for irrigation and drinking, and just less than $1 \%$ of fresh water resources are within human reach (Tiwari et al., 2003; Chauhan et al., 2021). Regarding the uneven distribution of fresh water in different regions of the world, the increase in demand due to population growth, and the essence of water for human survival and activities, desalination has gained more importance in recent years. Desalination is known as a treatment process of water that includes salt removal from saline water to make it appropriate for drinking (Mito et al., 2019). Desalination of water with the salinity more than normal levels is one of the ways (Tzen and Morris, 2003), and probably the most applicable one, to overcome the mentioned problems related to the unavailability of fresh water. The nature of the desalination process is energy-

\footnotetext{
Abbreviations: ANFIS, adaptive neuro-fuzzy inference system; ANN, artificial neural network; BP, backpropagation; FF, feed forward; GA, genetic algorithm; ICM, imperialist competition method; MLP, multilayer perceptron; MLR, multiple linear regression; PSO, particle swarm optimization; PV, photovoltaic; RBF, radial basis function; RF, random forest; RO, reverse osmosis; SVM, support vector machine.
} 
consuming, and it is crucial to properly supply the required energy. Improving the efficiency of the systems and utilizing the renewable energy sources are recommended to solve the problems related to the energy demand of desalination systems. Renewable energy sources can be used for desalination in direct and indirect ways. In direct approaches, thermal energy is mainly used for water evaporation and reducing the salinity of water, while renewable energies can be used for indirect desalination by producing electricity and applying the power in reverse osmosis (RO) technologies (Caldera et al., 2016). Among the renewable energy sources, solar energy is attractive for the desalination purpose since it can be used in different ways such as thermal technologies or photovoltaic/RO systems.

Numerous studies have been performed on the various kinds of solar-based desalination systems to find the influential factors and improve their performance (Mostafa et al., 2020). Depending on the type of solar desalination, the factors affecting the performance can be differed. Solar radiation is one of the most important factors on the output of the systems. For instance, Joseph et al. (2005) found that by increasing the solar radiation from $400 \mathrm{~W} / \mathrm{m}^{2}$ to $900 \mathrm{~W} / \mathrm{m}^{2}$, the efficiency of a single-stage solar desalination system increased from 15 to $26 \%$. In addition to solar radiation, the components of the system and their configuration affect the performance of these systems. As an example, Altarawneh et al. (2020) investigated the performance of a solar still composed of two parabolic troughs and two rectangular absorbers under different working conditions. They found that the rim angle of the troughs can influence the productivity of the desalination. Moreover, it was observed that reducing the pressure could remarkably improve the productivity of the desalination system. In another work, Geng et al. (2021) investigated the performance of an RO system powered by a solar dish Stirling engine. They found that by an increment in the temperature of the absorber, productivity of water increased, while there was an optimum temperature at which the exergy efficiency of the system reached its maximum value. In addition to the technical aspects, solar desalinations have been investigated from the economic point of view. For instance, Kettani and Bandelier (2020) carried out technoeconomic assessment on large-scale solar powered desalination systems in Morocco by considering photovoltaics (PVs) and concentrated solar power (CSP) for supplying energy. They found that using the PV/RO system without a storage unit is the cheapest configuration today and by 2030. In another work (Zheng and Hatzell, 2020), solar thermal desalination was thermo-economically analyzed, and it was found that construction costs of solar collectors were the largest total investments of the system. Other types of desalination systems have been modeled by using data-driven methods. For instance, Faegh et al. (Faegh et al., 2021) applied different artificial neural network (ANN)-based methods to model the gain output ratio and heat transfer rate of the evaporator and evaporative condenser of a heat pump-assisted desalination system and found that the R-squared of the models were more than 0.91 for all the outputs.

As mentioned in the previous paragraph, the performance of desalination units is affected by several elements such as the applied technology, operating conditions, and the properties of the saline or brackish water. Since the experimental works are costly and time-consuming, it would be useful to propose models for performance prediction and assessment of the desalination systems. Data-driven methods, with outstanding ability in modeling of complex systems, would be attractive options for performance forecasting of desalination systems (Gao et al., 2007; Chauhan et al., 2020; Adda et al., 2021). These methods have shown their outstanding performance in a wide variety of applications such as predicting the properties of materials (Ramezanizadeh et al., 2019a; Ramezanizadeh et al., 2019b), fault diagnosis (Venkatasubramanian and Chan, 1989), etc. (Rezaei et al., 2018). Current works focus on providing a comprehensive review on the applications of data-driven methods in modeling the performance of various solar desalination systems, which is performed for the first time. In addition, a table is prepared that summarizes the main findings of the reviewed works, inputs of the proposed models, applied approaches, and algorithms, which will be useful for the scholars working on the similar fields of study. Finally, according to the knowledge of the authors and the investigation of the previous studies, some suggestions are recommended for future works in the relevant subjects. The findings and information represented in this study will facilitate upcoming works to concentrate on the modeling of desalinations systems, especially the ones using solar energy.

\section{MOSTLY USED DATA-DRIVEN METHODS}

There are different data-driven methods used in modeling of energy systems. The mostly used approaches in energy system modeling are multilayer perceptron (MLP) ANN, adaptive neuro-fuzzy inference system (ANFIS), radial basis function (RBF), and support vector machines (SVMs). In this regard, these approaches are briefly described in the following subsections.

\section{Multilayer Perceptron Artificial Neural Network}

The structure of MLP is shown in Figure 1. As shown in this figure, there are three main layers in the simplest form of this network including input, hidden, and output. However, the hidden layer may be composed of more layers. In each node of this network, a weight vector is used to make connection between the current node and the ones in the upcoming layer. In the primary layer of the network, the summation of the values is sent to the next layer, which plays a role as inputs of that layer. Assuming that the vector of $\mathrm{X}$ is the model input and $n_{j}$ is applied as the $j t h$ node, the input in the upcoming layer is written as Eq. 1

$$
n_{j}=\sum_{i=1}^{n} \omega_{j i} x_{i}+\theta j \quad j=1,2, \ldots, K
$$

where $\theta j, \omega_{j i}$, and $\mathrm{K}$ are the threshold of the $j$ th node, the weight value of the node, and the number of nodes, respectively. 


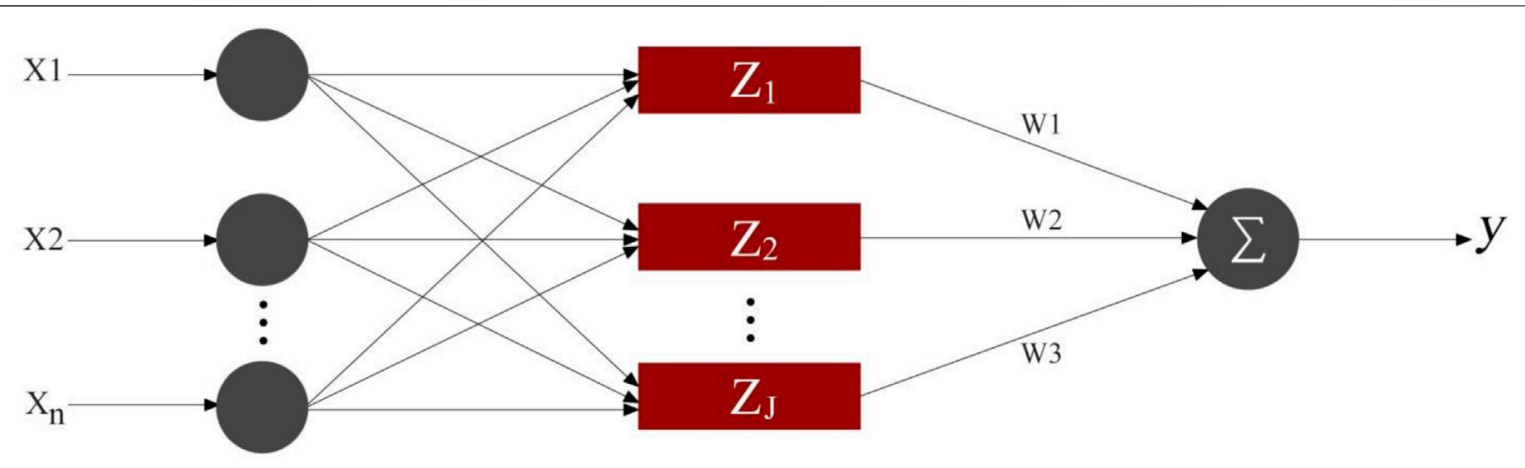

FIGURE 1 | Structure of MLP-ANN (Ramezanizadeh et al., 2019c).

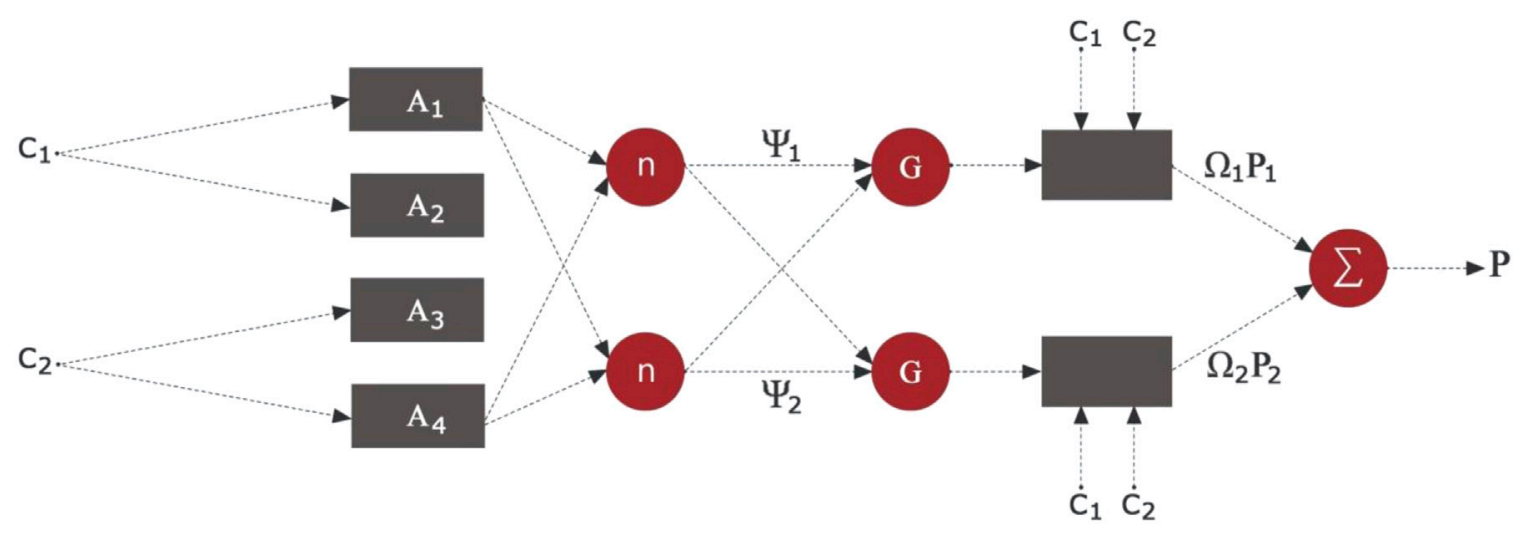

FIGURE 2 | Structure of the ANFIS model (Ramezanizadeh et al., 2019c).

Subsequently, $\mathrm{f}$ as a transfer function is applied to provide the overall inputs in the upcoming layer as represented in Eq. 2

$$
y_{j}=f\left(n_{j}\right)=f\left(\sum_{i=1}^{n} \omega_{j i} x_{i}+\theta_{j}\right) \quad j=1,2, \ldots, K
$$

Different functions can be used in this step with its own features and characteristics. By multiplying the linking weight and the output of the hidden layer, the output of the nodes will be determined. It should be noted that the architecture of the network including the number of hidden layers and neurons is dependent on the problem complexity, the noise of data, and the shares of data used for the test and validation of the model (Du and Swamy, 2006). By applying an iterative process, neurons are added in the procedure of training till it reaches the optimum state. The training process plays a key role in modeling by using this approach. Predicting the process by using this method is conducted by adjusting weight and bias values. Backpropagation (BP) is one of the mostly used training algorithm for adjusting these values (Goh, 1995). The main advantages of ANNs are their ability in synthesizing algorithms through the process of learning, providing solution for nonlinear problems, and robustness of the models; however, the main disadvantages are the necessity of training for each problem, requirement for multiple tests to find the most appropriate architecture, and large data requirement for training the network (Navarro, 2013).

\section{Adaptive Neuro-Fuzzy Inference System}

The schematic of ANFIS in a simple form with two inputs and one output is illustrated in Figure 2. In this architecture, five layers are considered. The first layer of this model is applied in order to change the inputs to fuzzy sets and projects the variables on fuzzy membership in the range between 0 and 1 . In the second layer, the signals of the input are generated; furthermore, values of membership function weight will be checked. In the next layer of this network, normalized firing strength of each node is obtained. Subsequently, the outputs are changed to crisp sets in the fourth layer. Finally, the outputs are determined in the last layer of the proposed network. This layer of the network contains one node which is used to sum up the input signals provided by the prior layer.

There are some advantages in the ANFIS method such as its ability in capturing the nonlinear structure of a procedure and fast learning capacity. In addition, this approach has both linguistic and numerical knowledge. In comparison with MLP ANN, ANFIS is more transparent for the users and results in less memorization error (Şahin and Erol, 2017); however, ANNs can 


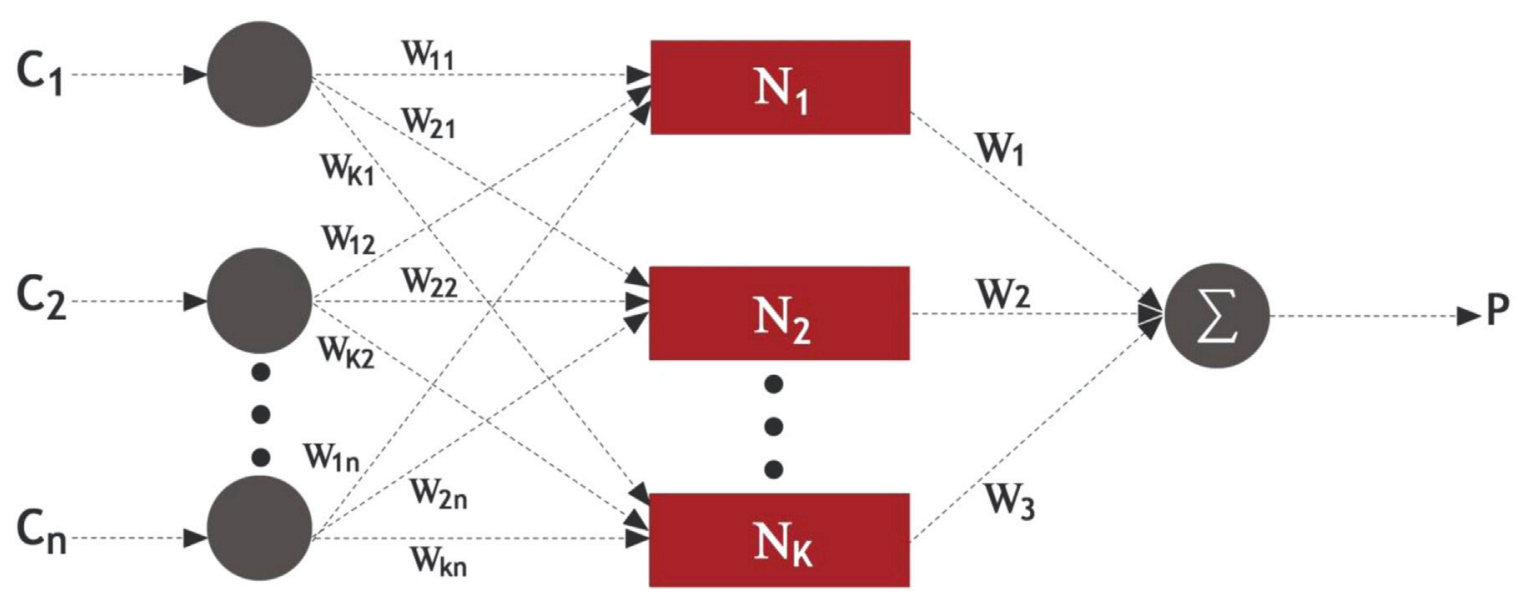

FIGURE 3 | Structure of the RBF model (Ramezanizadeh et al., 2019c).

have superior performance in accuracy of model outputs for test data compared with ANFIS (Atmaca et al., 2001).

\section{Radial Basis Function}

The RBF network has some advantages such as fast performance, a simple structure, and high estimation. The structure of this network is shown in Figure 3. Similar to MLP, there are three main layers in this network. The nodes are connected to the previous one in each layer of the network. In the first layer, input variables are assigned to the nodes. Subsequently, they are transferred to the next layer. At the final stage, the weighted links are used to transfer the data to the third layer. In the hidden layer of these networks, RBF plays the role of activation functions to produce the vector distance multiplied by the corresponding bias.

In the second layer of the mentioned network, the input vector will be projected to a new space (Zendehboudi and Tatar, 2017). To determine the output of the $j$ th neurons, Eq. 3 is applied as follows:

$$
Z_{j}=Z\left(\left\|X-\Delta_{j}\right\|\right)=\exp \left(-\frac{\left\|X-\Delta_{j}^{2}\right\|}{2 \xi_{j}^{2}}\right)
$$

In Eq. 3, $\Delta_{j}$ is the weight factor, $X$ is the input vector, $Z$ is the $\mathrm{RBF}$, and $\xi_{j}$ refrs to standard deviation. To calculate the standard deviation, the following equation is used:

$$
\xi=\frac{\theta_{m}}{\sqrt{\Lambda}}
$$

In Eq. 4, $\theta_{m}$ is the maximum distance between the centers and $\Lambda$ refers to number of centers. In the last layer of the network, weights of the signals are obtained by using the previous layer data

$$
\gamma=\sum_{j=1}^{A} \omega_{j} Z_{j}
$$

In Eq. 5, $\omega_{j}$ refers to the value of the weight vector determined in the training process. Despite some advantages of RBF networks compared with MLP ANN such as a faster training process, their accuracy in modeling the test data may be lower compared with MLP ANN (Markopoulos et al., 2016).

\section{Support Vector Machine}

SVM can be applied for regression and prediction in different systems (Sreedhara et al., 2019). By considering that $N_{s}$ is the number of data set samples and the inputs of $x_{k} \in R^{n}$ and $\mathrm{K}=$ $1,2, \ldots, \mathrm{N}$ and the outputs are $y_{k} \in R$, the SVM formulation is as follows (Ramezanizadeh et al., 2019a; Essa et al., 2020):

$$
y=w^{t} \varphi(x)+b
$$

In Eq. 6, b and $\mathrm{w}$ are the bias and weight, respectively (Ahmadi and Mahmoudi, 2016; Ramezanizadeh et al., 2019c). $\varphi(x)$ denotes a nonlinear function which is applied to transfer $x_{k}$ to a high-dimension space. Generally, this changes to an optimization problem which can be expressed as follows:

$$
\mathrm{F}(w)=\frac{1}{2} w^{T} w+\gamma \sum_{k=1}^{N_{s}} e_{k}^{2}
$$

subject to

$$
y_{k}=w^{T} \varphi\left(x_{k}\right)+b+e_{k} \quad k=1,2, \ldots, N_{s}
$$

In Eq. 7, $\gamma$ and $e_{k}$ are the regularization parameter and error value, respectively (Ahmadi and Mahmoudi, 2016; Ramezanizadeh et al., 2019c). Eqs. 7 and 8 can be rewritten as follows:

$$
y=\sum_{k=1}^{N_{s}} \alpha_{k} K\left(x, x_{k}\right)+b
$$

where $\alpha_{k}$ is the Lagrange multiplier and $K\left(x, x_{k}\right)$ is the kernel function. In some studies (Essa et al., 2020), the RBF kernel function is used, which is defined as follows: 


$$
K\left(x, x_{k}\right)=\exp \left(-\left\|x_{k}-x^{2}\right\| / \sigma^{2}\right)
$$

In this equation, two parameters including $\sigma$ and Lagrange multipliers must be determined. One of the main advantages of SVM methods for modeling is their ability in providing nonlinear solutions, while the main problem associated with this approach is the requirement for knowledge about the kernel that must be used.

Generally, mean square error (MSE) and R-squared are used in evaluation of regression and predictive models, which are as follows:

$$
\begin{gathered}
\text { MSE }=\frac{\sum_{i=1}^{n}(\text { predicted value }- \text { actual value })^{2}}{n s} \\
R^{2}=1-\frac{\sum_{i=1}^{i=n}\left(y_{i}^{\text {actual value }}-y_{i}^{\text {predicted value }}\right)^{2}}{\sum_{i=1}^{i=n}\left(y_{i}^{\text {actual value }}-\overline{y^{\text {actual value }}}\right)^{2}}
\end{gathered}
$$

where ns is the number of samples used in regression.

\section{APPLICATIONS OF DATA-DRIVEN METHODS IN SOLAR DESALINATIONS}

There are three main principle approaches used for desalination, which are thermal, pressure, and electrical. Thermal distillation can be considered as the oldest approach in which water with high salinity is boiled and the generated steam is collected. The condensed form of the collected steam can now be used as fresh water. In the electrical approach, electrical current is applied to separate the salt and water. In these types of desalination units, a permeable membrane is used, in which ions move across it by use of electric current as a driving force. In the RO type of desalination, pressure acts as a driver for moving water through a selectively permeable membrane, leaving the salt behind (Parise, 2011). The majority of the desalination market belongs to thermal and RO types. Although the majority of the installed capacity of desalination systems is of the RO type, there are some benefits in thermal desalinations. For instance, the waste heat of plants can be used for the thermal desalination units, which leads to a high overall efficiency of the system. The majority of the studies performed on the applications of data-driven methods in solar desalination systems have focused on thermal types (Elsheikh et al., 2021). For instance, Zarei and Behyad. (2019) employed ANN to model the output of a humidification-dehumidification-type solar desalination used for humidifying the interior space of the greenhouse and supplying fresh water. The inputs of the model were width and length of the seawater greenhouse, front evaporator height, and the roof transparency, and the output was water yield of the system. Their different structures with one and two hidden layers were examined. They observed that applying one hidden layer with nine neurons led to the highest exactness with $\mathrm{R}^{2}$ of 0.997 . In addition to the architecture of the model, the applied functions and optimization methods could affect the outputs of the models proposed for solar desalinations. For instance, Nazari et al. (2020) compared the performance of ANN with and without the imperialist competition algorithm (ICA) optimization method in forecasting energy and exergy efficiencies and productivity of single-slope solar stills. They noticed that using the optimization method led to significant reduction in mean absolute errors of the model in predicting the mentioned outputs by up to $54.3 \%$ for water productivity. In another work (Mashaly and Alazba, 2017a), the output of an inclined passive solar still fed by agricultural drainage water was modeled by applying ANN with different architectures and multiple linear regression (MLR). The inputs for the modeling of the instantaneous thermal efficiency were relative humidity, ambient temperature, solar radiation, wind speed, feed temperature and its total dissolved solids, and feed mass flow rate. They found that ANN outperforms MLR and the best structure was in the case of using six neurons in the hidden layer. In addition to differing numbers of neurons in the hidden layer, it would be useful in terms of exactness enhancement by changing the number of hidden layers (Ramezanizadeh et al., 2019b); however, it must be considered that an increase in the number of hidden layers may lead to overfitting.

The applied method and algorithm are among the most important factors that influence the exactness of the datadriven methods in forecasting the outputs of solar stills (Mashaly and Alazba, 2015; Mashaly and Alazba, 2017b; Mashaly and Alazba, 2018a; Mashaly and Alazba, 2018b; Mashaly and Alazba, 2019a). For instance, Wang et al. (2021) used random forest $(\mathrm{RF}), \mathrm{ANN}$, and multilinear regression to forecast the productivity of the system based on time, solar radiation intensity, wind speed, temperatures of feed water, basin plates, salt water, cover, and ambient temperature. They found that using RF led to the prediction with the least error compared with others. In order to reach further exactness, the Bayesian optimization algorithm was applied to search the most appropriate hyperparameters which led to significant enhancement in the accuracy of the ANN-based model by increasing the determination coefficient from 0.7098 to 0.9614 . In another study (Essa et al., 2020), the performance of ANN with the Harris Hawk optimizer was compared with the traditional ANN and SVM in predicting the productivity of an active solar still. In their models, ambient temperature, time, speed of wind, solar irradiance, and velocity of vapor were considered as inputs. They found that ANN outperformed SVM and could be further enhanced by using the optimizer. In their work, the R-squared values of the model for ANN and SVM were 0.9703 and 0.9701 , respectively, while this value for the ANN-based model coupled with the optimizer reached 0.9834 . Improved accuracy of the models through the coupling optimizer can be attributed to better adjustment of the parameters affecting the performance of the modeling approach. In another work, performance of ANFIS, ANN, and Multiple Regression (MR) in forecasting the performance of an inclined passive solar still was compared. In all the proposed models, solar radiation, relative humidity, feed flow rate, and total dissolved solids of brine and feed were used as inputs. The utilized function in the structure of data-driven 


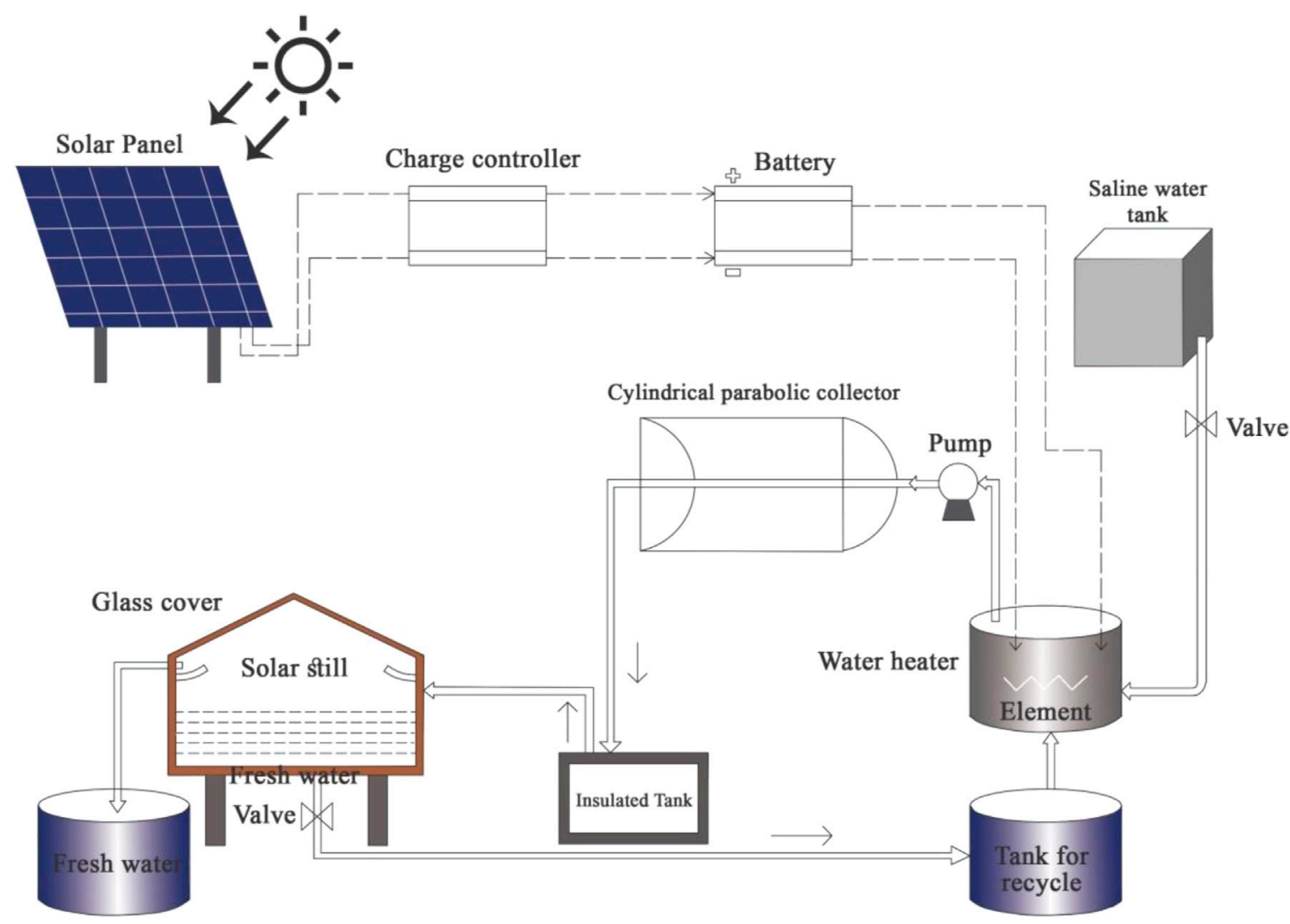

FIGURE 4 | Solar desalination system with a collector, heater, and PV (Bagheri et al., 2021).

methods is another influential factor. As an example, Mashaly and Alazba (2017c) tested different membership functions including triangle, trapezoid, Pi curve, and difference between two sigmoidal functions in ANFIS-based models to propose a model with the highest exactness. In their models, inputs were dissolved solids of the feed and brine, feed flow rate, relative humidity, and solar radiation. They found that the Pi curve and triangle membership functions can provide outputs with higher accuracy compared with the others. In cases of using these methods, the correlation coefficient of the regression for training data sets was around 0.999 . The most proper function in the structure of networks for modeling can be dependent on the physics of the problem which can be obtained by testing different types of functions.

In modeling the system with data-driven methods, it is essential to consider all the effective elements as inputs. In this regard, some models have included more inputs to reach better accuracy or improved the comprehensiveness. As an example, Abujazar et al. (2018) used wider variables such as cloud cover, day and month numbers, number of hours per day, difference between the temperatures of inner and outer surfaces of glass in addition to the factors used in the majority of the studies such as ambient temperature, solar radiation, humidity, wind speed, and temperatures of water, basins, and vapor to forecast productivity of an inclined stepper solar still. In their work, cascaded forward ANN with different numbers of neurons and a linear model and regression were used. They found that the ANN model was more reliable in predicting the productivity of the system. The values of root-mean-squared error (RMSE) for regression, the linear model, and the ANN-based model were 50.21, 80.36, and 41.01, respectively. Despite more comprehensiveness of this model compared with previously mentioned ones, it can be further improved by considering other factors such as the specifications of the system such as the dimensions of different parts and properties of the materials affecting the performance of the systems.

Solar desalination can be integrated with other components to reach higher productivity. Data-driven methods are applicable for performance forecasting of these systems (Bagheri et al., 2020). As an example, Bagheri et al. (2021) used ANN to model a solar desalination system composed of PVs, a heater, a battery, a cylindrical parabolic collector, etc. The panel was applied to supply the power of the heater used in the tank that was employed for preheating the saline water prior to its entrance to the collector. In the collector, saline water was further heated before entering the still. The schematic of the system is shown in Figure 4. By testing different architectures of the network and by varying the number of neurons in the hidden layer, they found that the highest accuracy of the model was obtained in the case of using 24 neurons with an $\mathrm{R}^{2}$ of 0.993 . These methods can be developed for other hybrid systems such as solar/wind RO desalination technologies in the near future; however, more 
inputs such as wind speed and other factors affecting the systems must be considered. Since the inputs of the systems are increased for hybrid technologies, the modeling process would be more complicated.

Data-driven methods are employable for modeling the dynamic performance of solar desalination systems. In a study carried out by Sohani et al. (2021), different ANNs including backpropagation (BP), feedforward (FF), and RBF were used to estimate water temperature and hourly water production of a solar still with enhanced design. The inputs of their models were wind speed, ambient temperature, received radiation from the Sun, and water depth in the basin. Comparison of the estimated data and the corresponding actual vales revealed that RBF and FF were the most powerful approaches in predicting water temperature and hourly water production, respectively. Despite its novel idea in dynamic modeling of a solar desalination, the comprehensiveness of their model was limited and could be further enhanced by considering other inputs such as wind speed and feed temperature.

Utilizing nanofluids in solar stills can improve their performance. Intelligent methods can be applied for accurate evaluation of these solar stills. Kandeal et al. (2021) tested various data-driven methods including ANN, Support Vector Regression (SVR), linear SVR, and RF to model the performance of a doubleslope solar still utilizing the carbon black nanofluid in $1.5 \% \mathrm{wt}$ concentration. The inputs of the proposed model were air ambient temperature, solar radiation, wind speed, vapor temperature, basin temperature, and temperatures at the glass inlet and outlet. The models were coupled with the Bayesian optimization algorithm to tune the approaches and obtain the outputs with the highest accuracy. They found that all the proposed models were able to predict the performance of the system with relatively high exactness; however, utilizing RF led to the highest accuracy. The performance of the nanofluidic solar desalination system integrated with other modules can be modeled by data-driven methods. For instance, Bahiraei et al. (2020) used ANN coupled with the genetic algorithm (GA) and Imperialist Competition Method (ICM) to model the performance of a nanofluidic solar still integrated with a thermoelectric module. The inputs of their model were time, solar radiation, ambient temperature, power of the applied fan, concentration of the nanofluid, and temperatures of water, glass, and basins, while the output of the proposed models was water productivity. They observed that the exactness of the model through coupling the mentioned optimization approaches significantly improved, while using ICM was more influential in terms of accuracy enhancement. In addition to the optimization method, the algorithm used for modeling affects the exactness of the predicted values of nanofluidic solar desalinations. For instance, Bahiraei et al. (2021) used Particle Swarm Optimization (PSO)-ANFIS and PSO-ANN for modeling the performance of a solar still with $\mathrm{Cu}_{2} \mathrm{O}$ nanoparticles. The inputs of the models were similar to those of the previous work, while the output of the designed model was efficiency of the system. They found that in both types of models, coupling the optimization methods led to exactness enhancement; however, the maximum accuracy in modeling was observed in the case of using PSO-ANFIS with an $\mathrm{R}^{2}$ of 0.9884 . In another work (Mashaly and Alazba, 2016), the performance of MLR and MLP ANN was compared in predicting the instantaneous thermal efficiency of a solar still. They found that using MLP ANN provided a model with higher exactness compared with MLR. Higher exactness of MLP ANN can be attributed to its more complex structure, which enables it to model the complicated systems with better performance.

The outputs of the ANN-based model can be used for designing an optimal condition for the performance of the desalination systems (Azad et al., 2021). As an example, in a study carried out by Porrazzo et al. (2013), an ANN-based optimizing control system was utilized for a solar-powered membrane desalination module. ANN was used for performance prediction of the system under different operating conditions by considering radiation and the rate of feed flow inlet temperature of cold channel as the inputs. Afterward, a control system was implemented to optimize the distillate production of the system. The proposed system allowed to set the feed flow rate at the optimal values in order to reach continuous maximum production of the distillate. As another example, Maleki et al. (2016) applied ANN to forecast the weather condition and optimize a hybrid system, solar-wind-powered RO desalination. By using the outputs of the network and performing optimization, the optimum design of the system was obtained.

To sum up the findings of the study, it can be declared that the accuracy of the models is under the influence of the applied method, optimization algorithm, etc. Generally, intelligent methods such as ANNs are preferred in terms of accuracy due to their more complex structures which enable them to model complicated systems with higher accuracy. In addition, it is found that applying optimization algorithms and coupling them with the intelligent methods improve the accuracy since the parameters affecting the exactness are used in their optimum values. In addition to the abovementioned factors, the considered inputs influence the exactness. Considering more influential factors as the inputs will provide more accurate models (Ahmadi et al., 2018). The other factors that may cause the differences in the model can be attributed to the noise of data, which is inevitable in experimental data used for modeling. In Table 1, the important outcomes of the studies in the topic of this article are provided.

\section{SUGGESTIONS FOR UPCOMING STUDIES}

Despite the fact that there are several works on utilization of datadriven methods in performance prediction of solar desalination systems, there are some limitations in modeling the outputs of solar desalination systems. For instance, it is difficult to propose comprehensive models with applicability for different types of solar-assisted desalination systems. For this purpose, the type of desalination must be defined as a meaningful variable. In addition, different working conditions may affect the performance of the systems, which must be distinguished and considered in inputs of the models. Furthermore, since the 
TABLE 1 | Important findings of the studies on applications of data-driven methods in solar desalination systems.

\begin{tabular}{llll}
\hline Reference & \multicolumn{1}{c}{ System } & \multicolumn{1}{c}{ Method } & \multicolumn{1}{c}{ Inputs } \\
\hline $\begin{array}{l}\text { Elsheikh et al. } \\
(2021)\end{array}$ & Stepped solar still & $\begin{array}{l}\text { Long short-term } \\
\text { memory } \\
\text { (LSTM) ANN }\end{array}$ & - \\
$\begin{array}{l}\text { Zarei and } \\
\text { Behyad (2019) }\end{array}$ & $\begin{array}{l}\text { Solar greenhouse desalination } \\
\text { (humidification-dehumidification) }\end{array}$ & ANN & Width and length of the seawater \\
Nazari et al. & Single-slope solar still & ANN & greenhouse, front evaporator height, \\
$(2020)$ & & and the roof transparency & Time, solar radiation, temperatures of \\
& & & ambience, glass, water, and basins
\end{tabular}

Mashaly and Alazba (2017a)

Inclined passive solar still

Mashaly and
Alazba (2019a)

Mashaly and

Alazba (2017b)
Solar still

Solar still

Solar still

(n)


TABLE 1 | (Continued) Important findings of the studies on applications of data-driven methods in solar desalination systems.

\begin{tabular}{llll}
\hline Reference & \multicolumn{1}{c}{ System } & \multicolumn{1}{c}{ Method } & \multicolumn{1}{c}{ Inputs } \\
$\begin{array}{l}\text { Bagheri et al. } \\
(2020)\end{array}$ & $\begin{array}{l}\text { Solar still with a battery, heater, PV, and } \\
\text { collector }\end{array}$ & $\begin{array}{l}\text { ANN and first } \\
\text { principle models }\end{array}$ & $\begin{array}{l}\text { Temperatures of water, basins, } \\
\text { insulation, ambience, and glass, solar } \\
\text { intensity, and speed of wind }\end{array}$ \\
$\begin{array}{l}\text { Bagheri et al. } \\
\text { (2021) }\end{array}$ & - & ANN \\
$\begin{array}{l}\text { Sohani et al. } \\
(2021)\end{array}$ & Solar still with improved design & FF, BP, and RBF & $\begin{array}{l}\text { Temperatures of water, basins, and } \\
\text { glass } \\
\text { wind speed, ambient temperature, } \\
\text { received radiation from the Sun, and } \\
\text { water depth in the basin }\end{array}$
\end{tabular}

Kandeal et al. Double-slope solar still with nanofluids SVR, Linear SVR, (2021)

Bahiraei et al. (2020)
Nanofluidic solar stills coupled with a thermoelectric
ANN, and FR

ANN with ICM

and $\mathrm{GA}$
Bahiraei et al (2021)

Mashaly and Alazba (2016)
Nanofluidic solar stills coupled with a thermoelectric

Solar still

MLR and ANN

PSO-ANFIS and PSO-ANN
Porrazzo et al. (2013)
Solar-powered membrane distillation unit

Inclined passive solar still
ANN, ANFIS, and MR
Air ambient temperature, solar radiation, wind speed, vapor temperature, basin temperature, and temperatures at the glass inlet and outlet

Time, solar radiation, ambient temperature, power of the applied fan, concentration of the nanofluid, and temperatures of water, glass, and basins

Time, solar radiation, ambient temperature, power of the applied fan, concentration of the nanofluid, and temperatures of water, glass, and basins Julian day, ambient temperature, relative humidity, solar radiation, wind speed, ambient temperature, feed water temperature, and total dissolved solids of brine and feed water

Radiation, rate of feed flow inlet temperature of the cold channel

Solar radiation, relative humidity, feed flow rate, and total dissolved solids of brine and the feed
Findings

Using ANN provided more accurate prediction. In the case of modeling water mass, $R^{2}$ of ANN and first principle models were 0.9998 and 0.9978 , respectively. $\mathrm{R}^{2}$ of the provided model was 0.993 .

RBF and FF showed the highest accuracy in forecasting water temperature and hourly water production, respectively. The $\mathrm{R}^{2}$ values for $\mathrm{FF}, \mathrm{BP}$, and $\mathrm{RBF}$ networks were 0.9631, 0.9425, and 0.9567, respectively.

Using RF led to the highest accuracy. The $R^{2}$ values for train data sets of SVR, linear SVR, ANN, and RF were 0.9905, 0.9569, 0.9867 , and 0.9971 , respectively.

Using ICM led to more enhancement in the accuracy of the ANN-based model compared with GA. The $R^{2}$ values of training data sets for MLP, GA-MLP, and ICM-MLP were 0.9458, 0.9495, and 0.9865 , respectively. Using PSO-ANFIS provided the predictions with the highest accuracy with an $\mathrm{R}$-squared of 0.9884 for training data sets.

ANN provided a model with higher exactness compared with MLR. The mean value of coefficient of correlation for ANN was $11.23 \%$ higher than the corresponding value of MLR. The values of $\mathrm{R}^{2}$ for training data sets of MLR and ANN were 0.856 and 0.996, respectively. A control system was proposed based on the ANN model to reach maximum productivity. The $\mathrm{R}$ value of the network for training data sets was 0.975 .

ANN showed superior performance

compared with the other approaches with a coefficient of correlation equal to 0.98 . experimental data are used for modeling, it may cause some problems due to different accuracies of measuring systems. Despite the mentioned problems and limitations, there are some recommendations that can improve the upcoming studies. First of all, the majority of the works are on thermal desalination modules, while these methods can be developed for the solar-powered RO systems and other desalination systems powered by solar-based hybrid systems such as solar/ geothermal or solar/wind. In addition, most of the proposed models are applicable for just one type of solar desalination, while their comprehensiveness can be improved by considering more inputs. For instance, using the dimensions of desalination systems is one of the ways that can be used to extend the application of the models. Furthermore, in the case of nanofluidic solar desalination, using the properties of nanofluids such as their concentration and properties of particles can lead to proposing a model with a higher level of applicability. Another point that must be considered in the future works is utilizing more recent optimization approaches to reach higher exactness. In this regard, hybrid optimization algorithms would be attractive options. Furthermore, it would be useful to use data-driven methods for other purposes such as modeling systems from economic and environmental points of view. In addition, the majority of the studies have focused on water productivity as the output of the model, while it would be useful and beneficial to model other technical criteria such as energy and exergy efficiency of the systems. Finally, it is suggested to compare different approaches in terms of the required time for the training process.

\section{CONCLUSION}

In the provided article, applications of data-driven methods in solar desalination system modeling are provided. Different variables have been used as the inputs in the models proposed for solar desalination systems including solar radiation, ambient 
conditions, etc. The main findings of this review article are as follows:

- Compared with the correlation, intelligent methods can model the solar desalination systems more accurately.

- Different parameters such as productivity, energy, and exergy efficiency can be modeled by using the intelligent methods.

- The accuracy of the suggested models is influenced by different elements such as the applied method and algorithm and the considered inputs.

- Coupling optimization methods with the models will improve the accuracy due to adjusting the hyperparameters to their optimum values.

- In addition to the applied method for modeling, the type of the optimization algorithm influences the exactness of the models.

- Operating conditions such as solar radiation and relative humidity in addition to the properties of the feed and saline water are among the most important factors that must be used as inputs.

- The outputs of the models, obtained by intelligent methods, can be used to optimize the systems.

- Most of the studies have considered water productivity as the output of the model, while it would be beneficial to

\section{REFERENCES}

Abujazar, M. S. S., Fatihah, S., Ibrahim, I. A., Kabeel, A. E., and Sharil, S. (2018). Productivity Modelling of a Developed Inclined Stepped Solar Still System Based on Actual Performance and Using a Cascaded Forward Neural Network Model. J. Clean. Prod. 170, 147-159. doi:10.1016/J.JCLEPRO.2017.09.092

Adda, A., Hanini, S., Bezari, S., Laidi, M., and Abbas, M. (2021). Modeling and Optimization of Small-Scale NF/RO Seawater Desalination Using the Artificial Neural Network (ANN). Environ. Eng. Res. 27, 200383. doi:10.4491/ eer. 2020.383

Ahmadi, M. A., and Mahmoudi, B. (2016). Development of Robust Model to Estimate Gas-Oil Interfacial Tension Using Least Square Support Vector Machine: Experimental and Modeling Study. J. Supercrit. Fluids 107, 122-128. doi:10.1016/J.SUPFLU.2015.08.012

Ahmadi, M., Hajizadeh, F., Rahimzadeh, M., Shafii, M., Chamkha, A., Lorenzini, G., et al. (2018). Application GMDH Artificial Neural Network for Modeling of $\mathrm{Al} 2 \mathrm{O} 3 /$ water and Al2O3/Ethylene Glycol thermal Conductivity. Int. J. Heat Technol. 36, 773-782. doi:10.18280/ijht.360301

Altarawneh, I., Batiha, M., Rawadieh, S., Alnaief, M., and Tarawneh, M. (2020). Solar Desalination under Concentrated Solar Flux and Reduced Pressure Conditions. Solar Energy 206, 983-996. doi:10.1016/J.SOLENER.2020.06.058

Atmaca, H., Cetisli, B., and Yavuz, H. S. (2001). "The Comparison of Fuzzy Inference Systems and Neural Network Approaches with ANFIS Method for Fuel Consumption Data," In Second International Conference on Electrical and Electronics Engineering Papers ELECO, 6, 1-4.

Azad, A., Aghaei, E., Jalali, A., and Ahmadi, P. (2021). Multi-objective Optimization of a Solar Chimney for Power Generation and Water Desalination Using Neural Network. Energ. Convers. Manage. 238, 114152. doi:10.1016/J.ENCONMAN.2021.114152

Bagheri, A., Esfandiari, N., Honarvar, B., and Azdarpour, A. (2020). First Principles versus Artificial Neural Network Modelling of a Solar Desalination System with Experimental Validation. Math. Comput. Model. Dyn. Syst. 26, 453-480. doi:10.1080/13873954.2020.1788609

Bagheri, A., Esfandiari, N., Honarvar, B., and Azdarpour, A. (2021). ANN Modeling and Experimental Study of the Effect of Various Factors on Solar Desalination. J. Water Supply Res. Technol. Aqua 70, 41-57. doi:10.2166/AQUA.2020.085 consider other technical criteria such as energy and exergy efficiency of the system.

- In addition to technical criteria, considering other factors such as environmental and economical parameters as outputs of the models would be useful.

- It is suggested to compare the intelligent models in terms of required time and calculations for the training process with different algorithms and approaches.

- Applying hybrid optimization algorithms, with more proper ability in finding optimal solutions, can lead to more precise models.

\section{AUTHOR CONTRIBUTIONS}

MA and MS have designed the work and contributed in writing and implementation of the work. IM and KY have contributed in implementation of the work and edition. BM edited the manuscript and contributed in writing.

\section{FUNDING}

This work was partially supported by Universiti Sains Malaysia under Short-term grant No. 304/PELECT/6315330.

Bahiraei, M., Nazari, S., Moayedi, H., and Safarzadeh, H. (2020). Using Neural Network Optimized by Imperialist Competition Method and Genetic Algorithm to Predict Water Productivity of a Nanofluid-Based Solar Still Equipped with Thermoelectric Modules. Powder Techn. 366, 571-586. doi:10.1016/J.POWTEC.2020.02.055

Bahiraei, M., Nazari, S., and Safarzadeh, H. (2021). Modeling of Energy Efficiency for a Solar Still Fitted with Thermoelectric Modules by ANFIS and PSOEnhanced Neural Network: A Nanofluid Application. Powder Techn. 385, 185-198. doi:10.1016/J.POWTEC.2021.03.001

Caldera, U., Bogdanov, D., and Breyer, C. (2016). Local Cost of Seawater RO Desalination Based on Solar PV and Wind Energy: A Global Estimate. Desalination 385, 207-216. doi:10.1016/J.DESAL.2016.02.004

Chauhan, R., Dumka, P., and Mishra, D. R. (2020). Modelling Conventional and Solar Earth Still by Using the LM Algorithm-Based Artificial Neural Network. Int. J. Ambient Energ. 1-8. doi:10.1080/01430750.2019.1707113

Chauhan, V. K., Shukla, S. K., Tirkey, J. V., and Singh Rathore, P. K. (2021). A Comprehensive Review of Direct Solar Desalination Techniques and its Advancements. J. Clean. Prod. 284, 124719. doi:10.1016/J.JCLEPRO.2020.124719

Du, K., and Swamy, M. (2006). Neural Networks in a Softcomputing Framework. Springer Science and Business Media.

Elsheikh, A. H., Katekar, V. P., Muskens, O. L., Deshmukh, S. S., Elaziz, M. A., and Dabour, S. M. (2021). Utilization of LSTM Neural Network for Water Production Forecasting of a Stepped Solar Still with a Corrugated Absorber Plate. Process Saf. Environ. Prot. 148, 273-282. doi:10.1016/J.PSEP.2020.09.068

Essa, F. A., Abd Elaziz, M., and Elsheikh, A. H. (2020). An Enhanced Productivity Prediction Model of Active Solar Still Using Artificial Neural Network and Harris Hawks Optimizer. Appl. Therm. Eng. 170, 115020. doi:10.1016/J.APPLTHERMALENG.2020.115020

Faegh, M., Behnam, P., Shafii, M. B., and Khiadani, M. (2021). Development of Artificial Neural Networks for Performance Prediction of a Heat Pump Assisted Humidification-Dehumidification Desalination System. Desalination 508, 115052. doi:10.1016/J.DESAL.2021.115052

Gao, P., Zhang, L., Cheng, K., and Zhang, H. (2007). A New Approach to Performance Analysis of a Seawater Desalination System by an Artificial Neural Network. Desalination 205, 147-155. doi:10.1016/J.DESAL.2006.03.549

Geng, D., Cui, J., and Fan, L. (2021). Performance Investigation of a Reverse Osmosis Desalination System Powered by Solar Dish-Stirling Engine. Energ. Rep. 7, 3844-3856. doi:10.1016/J.EGYR.2021.06.072 
Goh, A. T. C. (1995). Back-propagation Neural Networks for Modeling Complex Systems. Artif. Intell. Eng. 9, 143-151. doi:10.1016/0954-1810(94)00011-S

Joseph, J., Saravanan, R., and Renganarayanan, S. (2005). Studies on a Single-Stage Solar Desalination System for Domestic Applications. Desalination 173, 77-82. doi:10.1016/J.DESAL.2004.06.210

Kandeal, A. W., An, M., Chen, X., Algazzar, A. M., Kumar Thakur, A., Guan, X., et al. (2021). Productivity Modeling Enhancement of a Solar Desalination Unit with Nanofluids Using Machine Learning Algorithms Integrated with Bayesian Optimization. Energy Technol. 9, 2100189. doi:10.1002/ENTE.202100189

Kettani, M., and Bandelier, P. (2020). Techno-economic Assessment of Solar Energy Coupling with Large-Scale Desalination Plant: The Case of Morocco. Desalination 494, 114627. doi:10.1016/J.DESAL.2020.114627

Maleki, A., Khajeh, M. G., and Rosen, M. A. (2016). Weather Forecasting for Optimization of a Hybrid Solar-Wind-Powered Reverse Osmosis Water Desalination System Using a Novel Optimizer Approach. Energy 114, 1120-1134. doi:10.1016/J.ENERGY.2016.06.134

Markopoulos, A. P., Georgiopoulos, S., and Manolakos, D. E. (2016). On the Use of Back Propagation and Radial Basis Function Neural Networks in Surface Roughness Prediction. J. Ind. Eng. Int. 12, 389-400. doi:10.1007/S40092-016-0146-X

Mashaly, A. F., and Alazba, A. A. (2015). Comparative Investigation of Artificial Neural Network Learning Algorithms for Modeling Solar Still Production. J. Water Reuse Desalination 5, 480-493. doi:10.2166/WRD.2015.009

Mashaly, A. F., and Alazba, A. A. (2016). MLP and MLR Models for Instantaneous thermal Efficiency Prediction of Solar Still under Hyper-Arid Environment. Comput. Electron. Agric. 122, 146-155. doi:10.1016/J.COMPAG.2016.01.030

Mashaly, A. F., and Alazba, A. A. (2017). Thermal Performance Analysis of an Inclined Passive Solar Still Using Agricultural Drainage Water and Artificial Neural Network in Arid Climate. Solar Energy 153, 383-395. doi:10.1016/ J.SOLENER.2017.05.083

Mashaly, A. F., and Alazba, A. A. (2017). Artificial Intelligence for Predicting Solar Still Production and Comparison with Stepwise Regression under Arid Climate. J. Water Supply Res. Tec 66, 166-177. doi:10.2166/AQUA.2017.046

Mashaly, A. F., and Alazba, A. A. (2017). Application of Adaptive Neuro-Fuzzy Inference System (ANFIS) for Modeling Solar Still Productivity. J. Water Supply Res. Tec 66, 367-380. doi:10.2166/AQUA.2017.138

Mashaly, A. F., and Alazba, A. A. (2018). Membership Function Comparative Investigation on Productivity Forecasting of Solar Still Using Adaptive NeuroFuzzy Inference System Approach. Environ. Prog. Sustain. Energ. 37, 249-259. doi:10.1002/EP.12664

Mashaly, A. F., and Alazba, A. A. (2018). ANFIS Modeling and Sensitivity Analysis for Estimating Solar Still Productivity Using Measured Operational and Meteorological Parameters. Water Supply 18, 1437-1448. doi:10.2166/WS.2017.208

Mashaly, A. F., and Alazba, A. A. (2019). Comparison of Adaptive Neuro-Fuzzy Inference System and Multiple Nonlinear Regression for the Productivity Prediction of Inclined Passive Solar Still. J. Water Supply Res. Technol. Aqua 68, 98-110. doi:10.2166/AQUA.2019.058

Mashaly, A. F., and Alazba, A. (2019). Assessing the Accuracy of ANN, ANFIS, and MR Techniques in Forecasting Productivity of an Inclined Passive Solar Still in a Hot, Arid Environment. WSA 45, 239-250. doi:10.4314/ WSA.V45I2.11

Mito, M. T., Ma, X., Albuflasa, H., and Davies, P. A. (2019). Reverse Osmosis (RO) Membrane Desalination Driven by Wind and Solar Photovoltaic (PV) Energy: State of the Art and Challenges for Large-Scale Implementation. Renew. Sustain. Energ. Rev. 112, 669-685. doi:10.1016/j.rser.2019.06.008

Mostafa, M., Abdullah, H. M., and Mohamed, M. A. (2020). Modeling and Experimental Investigation of Solar Stills for Enhancing Water Desalination Process. IEEE Access 8, 219457-219472. doi:10.1109/ACCESS.2020.3038934

Navarro, R. I. (2013). Study of a Neural Network-Based System for Stability Augmentation of an Airplane Annex 1 Introduction to Neural Networks and Adaptive Neuro-Fuzzy Inference Systems (ANFIS). Technical Report. Catalunya.

Nazari, S., Bahiraei, M., Moayedi, H., and Safarzadeh, H. (2020). A Proper Model to Predict Energy Efficiency, Exergy Efficiency, and Water Productivity of a Solar Still via Optimized Neural Network. J. Clean. Prod. 277, 123232. doi:10.1016/ J.JCLEPRO.2020.123232

Parise, T. (2011). Water Desalination. Stanford University. Available at: http:// large.stanford.edu/courses/2011/ph240/parise2/.
Porrazzo, R., Cipollina, A., Galluzzo, M., and Micale, G. (2013). A Neural NetworkBased Optimizing Control System for a Seawater-Desalination Solar-Powered Membrane Distillation Unit. Comput. Chem. Eng. 54, 79-96. doi:10.1016/ J.COMPCHEMENG.2013.03.015

Ramezanizadeh, M., Ahmadi, M. A., Ahmadi, M. H., and Alhuyi Nazari, M. (2019). Rigorous Smart Model for Predicting Dynamic Viscosity of Al2O3/water Nanofluid. J. Therm. Anal. Calorim. 137, 307-316. doi:10.1007/s10973-018-7916-1

Ramezanizadeh, M., Alhuyi Nazari, M., Ahmadi, M. H., Lorenzini, G., and Pop, I. (2019). A Review on the Applications of Intelligence Methods in Predicting thermal Conductivity of Nanofluids. J. Therm. Anal. Calorim. 138 (1), 827-843. doi:10.1007/s10973-019-08154-3

Ramezanizadeh, M., Ahmadi, M. H., Nazari, M. A., Sadeghzadeh, M., and Chen, L. (2019). A Review on the Utilized Machine Learning Approaches for Modeling the Dynamic Viscosity of Nanofluids. Renew. Sustain. Energ. Rev. 114, 109345. doi:10.1016/J.RSER.2019.109345

Rezaei, M. H., Sadeghzadeh, M., Alhuyi Nazari, M., Ahmadi, M. H., and Astaraei, F. R. (2018). Applying GMDH Artificial Neural Network in Modeling CO2 Emissions in Four Nordic Countries. Int. J. Low-Carbon Tech. 13, 266-271. doi:10.1093/ijlct/cty026

Şahin, M., and Erol, R. (2017). A Comparative Study of Neural Networks and ANFIS for Forecasting Attendance Rate of Soccer Games. MCA 22, 43. doi:10.3390/MCA22040043

Sohani, A., Hoseinzadeh, S., Samiezadeh, S., and Verhaert, I. (2021). Machine Learning Prediction Approach for Dynamic Performance Modeling of an Enhanced Solar Still Desalination System. J. Therm. Anal. Calorim. 2021, 1-12. doi:10.1007/S10973-021-10744-Z

Sreedhara, B. M., Rao, M., and Mandal, S. (2019). Application of an Evolutionary Technique (PSO-SVM) and ANFIS in clear-water Scour Depth Prediction Around Bridge Piers. Neural Comput. Applic 31, 7335-7349. doi:10.1007/s00521-018-3570-6

Tiwari, G. N., Singh, H. N., and Tripathi, R. (2003). Present Status of Solar Distillation. Solar Energy 75, 367-373. doi:10.1016/J.SOLENER.2003.07.005

Tzen, E., and Morris, R. (2003). Renewable Energy Sources for Desalination. Solar Energy 75, 375-379. doi:10.1016/J.SOLENER.2003.07.010

Venkatasubramanian, V., and Chan, K. (1989). A Neural Network Methodology for Process Fault Diagnosis. Aiche J. 35, 1993-2002. doi:10.1002/AIC.690351210

Wang, Y., Kandeal, A. W., Swidan, A., Sharshir, S. W., Abdelaziz, G. B., Halim, M. A., et al. (2021). Prediction of Tubular Solar Still Performance by Machine Learning Integrated with Bayesian Optimization Algorithm. Appl. Therm. Eng. 184, 116233. doi:10.1016/J.APPLTHERMALENG.2020.116233

Zarei, T., and Behyad, R. (2019). Predicting the Water Production of a Solar Seawater Greenhouse Desalination Unit Using Multi-Layer Perceptron Model. Solar Energy 177, 595-603. doi:10.1016/J.SOLENER.2018.11.059

Zendehboudi, A., and Tatar, A. (2017). Utilization of the RBF Network to Model the Nucleate Pool Boiling Heat Transfer Properties of Refrigerant-Oil Mixtures with Nanoparticles. J. Mol. Liquids 247, 304-312. doi:10.1016/J.MOLLIQ.2017.09.105

Zheng, Y., and Hatzell, K. B. (2020). Technoeconomic Analysis of Solar thermal Desalination. Desalination 474, 114168. doi:10.1016/J.DESAL.2019.114168

Zheng, H. (2017). General Problems in Seawater Desalination. Solar Energ. Desalination Techn., 1-46. doi:10.1016/B978-0-12-805411-6.00001-4

Conflict of Interest: The authors declare that the research was conducted in the absence of any commercial or financial relationships that could be construed as a potential conflict of interest.

Publisher's Note: All claims expressed in this article are solely those of the authors and do not necessarily represent those of their affiliated organizations or those of the publisher, the editors, and the reviewers. Any product that may be evaluated in this article or claim that may be made by its manufacturer is not guaranteed or endorsed by the publisher.

Copyright () 2021 Alhuyi Nazari, Salem, Mahariq, Younes and Maqableh. This is an open-access article distributed under the terms of the Creative Commons Attribution License (CC BY). The use, distribution or reproduction in other forums is permitted, provided the original author(s) and the copyright owner(s) are credited and that the original publication in this journal is cited, in accordance with accepted academic practice. No use, distribution or reproduction is permitted which does not comply with these terms. 